\title{
Модель межотраслевого (межтематического) существования современного печатного СМИ: аспекты реализации и потенциальные положительные перспективы
}

\author{
Хмелев А.В. \\ Сибирский государственный университет телекоммуникации и информатики, \\ Россия, 630102, г. Новосибирск, ул. Гурьевская, 51 \\ E-mail: ah.04@mail.ru
}

\begin{abstract}
Аннотация. В данной статье проведено изучение вопроса использования межотраслевой (межтематической) модели современных печатных средств массовой информации, используемой для решения проблемы стабилизации показателей конкурентоспособности (экономических и статистических). Изучение данной модели в сфере массмедиа строится на теории стабилизации показателей (общий объем, рекламный объем), на основе синхронизации работы нескольких разделов, относящихся к разным сферам (отраслям) в одном проекте (СМИ). Для реализации подобной модели нужно учесть ряд важных аспектов, один из главных - это вопрос календарного колебания активности в разных сферах. Данный вопрос изучен на примере сфер экономики и спорта, посредством анализа изменений показателей, средств массовой информации, относящихся к данным сферам. Произведена оценка перспектив развития (усиления позиции на рынке), расширения возможностей (увеличения охвата рекламодателей, и расширения потенциала электронных ресурсов), поддержания конкурентоспособности (возможность обновления частей одного бренда) и деления на несколько проектов при использовании такой модели в современных условиях.
\end{abstract}

Ключевые слова: издания, конкуренция, тематические разделы, календарное колебание, стабилизация, перспективы.

Для цитирования: Хмелев А.В. 2021. Модель межотраслевого (межтематического) существования современного печатного СМИ: аспекты реализации и потенциальные положительные перспективы. Экономика. Информатика, 48 (2): 274-286. DOI 10.52575/2687-0932-2021-48-2-274-286.

\section{Model of intersectoral (interthematic) existence of modern print media: implementation aspects and potential positive prospects}

\author{
Alexey V. Khmelev \\ Siberian State University of Telecommunications and Information Sciences, \\ 51 Guryevskaya St, Novosibirsk, 630102, Russia \\ E-mail: ah.04@mail.ru
}

\begin{abstract}
This material is devoted to the study of the use of the intersectoral model in the field of modern media, for solving such problems as competitiveness and stabilization. These tasks are implemented based on the synchronization of the work of several sections related to different areas (branches) in one project. Special attention is paid to the consideration of the theory of calendar fluctuations in activity on the example of existing mass media, namely, changes in their content (total volume and advertising) during the year. An assessment was made of the prospects for development (strengthening the position in the market), expanding opportunities (increasing the coverage of advertisers, and expanding the potential of electronic resources), maintaining competitiveness (the possibility of updating parts of one brand) and dividing (into several projects) when using such a model in modern conditions.
\end{abstract}

Keywords: editions, competition, thematic sections, calendar fluctuations, stabilization, prospects. 
For citation: Khmelev A.V. 2021. Model of intersectoral (interthematic) existence of modern print media: implementation aspects and potential positive prospects. Economics. Information technologies, 48 (2): 274 286. (in Russian). DOI 10.52575/2687-0932-2021-48-2-274-286.

\section{Введение}

При всей стремительной динамике развития современных электронных медиа-ресурсов печатные издания остаются с точки зрения продвижения - очень сильным рекламным инструментом, с точки зрения соискателей работы - привлекательным местом работы, с точки зрения владения - прибыльным активом, ежемесячные денежные поступления могут быть от 450 тысяч рублей до 12 миллионов рублей [Хмелев, 2017; Зверева, 2019]. Так, в качестве примера можно привести печатное издание «Аргументы и факты на Оби» (Новосибирск) - в 2019 году полоса рекламы стоила 99,6 тысячи рублей [Прайс-лист «АиФ на Оби»]. Это информационное издание, и согласно законам «о рекламе» и «о средствах массовой информации» оно не может размещать рекламы больше $45 \%$ от объема. Согласно официальным данным на 14.11.19, минимальный объеме газеты обозначен в 24 полосы, соответственно объем рекламы равен 10,8 полос, то есть доход с одного выпуска 1076328 рублей, в месяц выходит четыре выпуска, что дает в итоге примерно 4305312 рублей поступлений.

Но для того чтобы все эти положительные экономические аспекты имелись и сохранялись на стабильном уровне, нужны умелые и продуманные действия в области управления, маркетинга и поддержания конкурентоспособности данного актива. Ключевыми проблемами для современных печатных средств массовой информации можно обозначить:

- Стабилизацию показателей общего объема и рекламного объема;

- Увеличение целевой аудитории издания;

Так как данные проблемы тесно взаимосвязаны, возникает потребность в инструменте, который позволял бы их решить (или единовременно, или поступательно), в качестве такого инструмента стоит рассмотреть модель межотраслевой (межтематической) формы существования издания. Данная модель характеризуется наличием нескольких крупных разделов, относящихся к разным отраслям (сферам) внутри одного издания. Данная модель учитывает ряд важных моментов. Во-первых, тот факт, что в сфере средств массовой информации очень высока конкурентная плотность [Тамберг, Бадьин, 2005; Доктор, 2013]. Одной из особенностей конкуренции среди средств массовой информации является то, что крупные издания в качестве конкурентов воспринимают только издания такого же склада (конструкции), если брать официальную терминологию, то это издания, ориентированные на тот же тематический сегмент рынка, тех же рекламодателей, тех же читателей [Амблер, 1999]. Есть так же особенные случаи в российской экономике, когда в одном сегменте существует два крупных издания, но при этом их конкуренция сведена к минимальному значению, так как у них разное позиционирование и формы подачи материалов. Это позволяет им мирно сосуществовать в одном сегменте [Мудров, 2008; Огилви, 2005; Тамберг, Бадьин, 2005]. Вовторых, специфику узкопрофильных изданий. Многие крупные издания являются специализированными (узкопрофильными) и существуют в рамках одной конкретной отрасли или же в рамках одной конкретной специфики. Так, например, издание Status - это финансовоэкономическое издание, которое даже позиционирует себя как «Бизнес-журнал для состоявшихся людей», или же издание ПРЕДСЕДАТЕЛЬ - журнал обо всем, что происходит в агропромышленном комплексе (АПК) [Журнал Status; Журнал Председатель]. Так же примером можно считать журнал «ИНФОСФЕРА», который охватывал сферу связи - теле- и радиовещания и все связанные аспекты, такие как кабельное, спутниковое и иное техническое оборудование [Журнал Инфосфера]. Необходимо выделить еще один важный аспект узкопрофильных изданий, на их показателях (общий объем, объем рекламных средств) сильно отражается календарное колебание, ведь в каждом сегменте рынка или отрасли есть 
промежутки с высокой и низкой активностью её участников. Если общий объем узкопрофильные издания еще могут компенсировать увеличением редакционного материала, то с рекламными объемами все на порядок сложнее, отсутствие профильной рекламы нельзя компенсировать ни тематической, ни профильной, что может привести к падению имиджа и оттоку читателей и рекламодателей.

Как выше уже отмечалось, особенностью предлагаемой модели является синхронизация двух разделов, относящихся к разным отраслям (сферам). Естественно, что данный аспект зависит от календарного колебания в выбранных отраслях (сферах), что приводит к необходимости детального изучения данного параметра или теории календарного колебания. В данном материале будет рассмотрена данная теория посредством изучения синхронизации тематических сфер - экономики и спорта, а в рамках изучения будет представлена теория календарного колебания для каждой из обозначенных сфер, изучено колебание показателей реально существующих изданий в данных направлениях. Также произведена оценка потенциальных возможностей существования в межотраслевой модели, в частности решения вышеобозначенных ключевых проблем, и проанализированы наиболее возможные положительные перспективы, которые могут возникнуть, и сложности их реализации. В качестве базы данных будут использованы открытые архивы изданий (печатных и электронных), при этом для обработки данных был использован метод сбора и обобщения (метод синтеза) с учетом требований законов «о средствах массовой информации» и «о рекламе».

\section{Основные результаты исследования}

Для построения теоретической шкалы активности используются следующие обозначения в материале:

1 - максимальная активность компаний в определённой тематике;

0,75 - высокая активность компаний в определённой тематике;

0,5 - средняя активность компаний в определённой тематике;

0,3 - переменная активность компаний в определённой тематике;

0,25 - низкая активность компаний в определённой тематике;

0 - отсутствие активности среди компаний в определенной тематике.

Первой будет изучена сфера экономики, для этого ниже на диаграмме приведена теория рекламной активности компаний данной сферы в течение года.

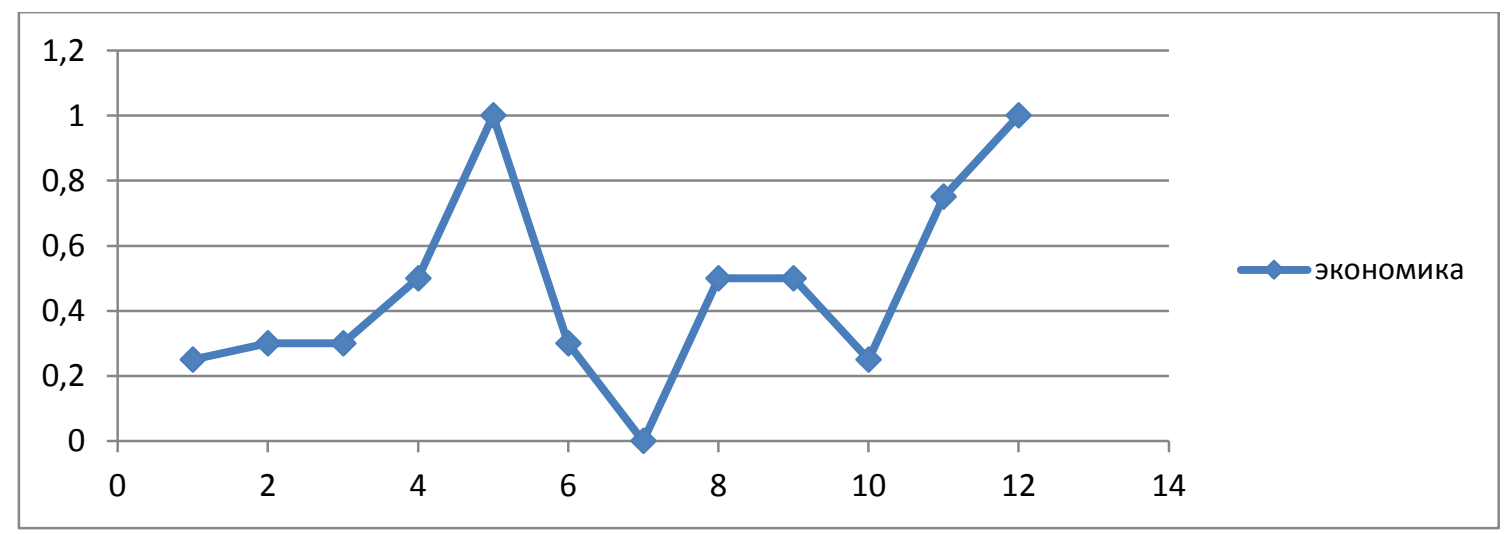

Рис. 1. Активность компаний, относящихся к разделу о экономике, в течение года Fig. 1. Activity of companies related to the section on the economy during the year Источник: составлено автором на основе теории.

Более детальное пояснение по диаграмме активности.

Отрезки январь-март и ноябрь-декабрь сильно взаимосвязаны. В первую очередь это тот факт, что рекламные материалы для первого номера (если он в январе-феврале) 
сотрудники издания согласуют в декабре, и так же проходит оплата данных материалов, так как в дальнейшем на новогодние выходные большая часть руководителей уезжает. В конце года многие компании дают материал, который освещает их положительные итоги, а также есть большое количество материалов поздравительного характера, этот факт также влияет на показатель рекламной активности. Низкая активность в начале года обусловлена двумя факторами. Первый - это большое количество праздничных дней в январе, и соответственно начало работы 9-11 числа. Второй - это тот факт, что в январе только формируется и согласовывается рекламный фонд на год (соответственно большая часть рекламы в них - это ранее согласованные материалы, оплаченные в предшествующем году и из фонда предшествующего года). В качестве примера можно привести журнал «ИНФОСФЕРА», одно из ключевых мероприятий данного издания - это выставка CSTB, которая проходит в конце января - начале февраля, отдельного номера в январе у данного издания не было, оно выпускало декабрьский (новогодний) номер, где размещало пресс-релиз данной выставки, и соответственно реклама всех, кто был заинтересован в рекламе на данной выставке через данный ресурс и оплата всех материалов осуществлялась в декабре.

Отрезки апрель-май и середина августа - сентябрь - в этих отрезках наблюдается активность (от средней до максимальной). В этих отрезках очень много мероприятий (выставок и форумов), которые могут выступить в качестве информационного повода для выхода очередного выпуска, например, если провести мониторинг по г. Новосибирск, получается, что в 2019 году 12 из 19 мероприятий проходили в данных промежутках времени. В частности, в весенней части «форум «ИТМСибирь»» (май), что касается осеннего отрезка, одно из ключевых мероприятий это «форум «Технопром»» (сентябрь). На подобных мероприятиях присутствуют руководители области, мэрии, профильных министерств, а также руководители и эксперты коммерческих компаний, стоит также отметить, что на подобных мероприятиях подписывается множество договоров о сотрудничестве и данные события компании также предпочитают освещать в прессе.

Отрезок спада - это промежуток с середины июня по середину августа, спад характеризован большим количеством отпусков, в том числе и руководителей компании. Также если ознакомиться, например, с календарем выставок и форумов в г. Новосибирске - в данном отрезке нет мероприятий (в конце мая большинство мероприятий заканчиваются, а новые крупные мероприятия предстоят только в сентябре).

В описании всех отрезков большое внимание уделялось наличию или отсутствию мероприятий (выставок и форумов). Для понимания важности такого мероприятия для печатного издания оптимально рассмотреть практический пример. Так, в 2016 году журнал «ИНФОСФЕРА» готовил очередной осенний номер, который традиционно привязан к выставке NATEXPO (Москва). Но по экономическим причинам руководство приняло решение отказаться от участия в выставке, что привело к тому, что из 12 постоянных клиентов (кто ежегодно участвовал в осеннем номере) отказались 7 , издание потеряло 24,7 \% от всей планируемой рекламы.

Для подтверждения вышепредставленного графика (рис. 1) проведем анализ наполнения журналов, относящихся к экономике, бизнесу и финансам. К таковым можно отнести журнал NetWorker, Status и LEADERSTODAY (ранее журнал СТИЛЬ). Стоит пояснить, что при изучении архивов номеров этих журналов за 2018 год, в качестве рекламного наполнения будет учитываться весь контент с пометками «реклама» и «размещено на правах рекламы», так как этого требует закон о рекламе (табл. 1).

Для большей наглядности преобразуем полученные данные в диаграммы, рис. 2 (изменения общего объема) и рис. 3 (изменения рекламного объема).

Как видно из вышепредставленного графика, есть много точек совпадений с ранее предложенной концепцией колебания в области экономики (рис. 1). Для начала о журнале LEADERSTODAY: есть небольшие расхождения в начальной стадии графика (январь) и в финальной (декабрь). Данное отклонение можно аргументировать тем фактом, что часть материалов переводят с декабрьского номера в январский для того, чтобы не было высокой 
разницы в параметрах наполнения. Также виден провал в летнем промежутке, который совпадает с теорией, изложенной на рис. 1, данный провал выглядит менее выделяющимся, и в этой ситуации есть логическое объяснение: руководство журнала выпустило 11, а не 12 номеров, седьмой номер является по факту двумя номерами, соединёнными в один, поэтому у него такой значимый размер и именно по этой причине после него следует провал. Один номер в 156 страниц выглядит весьма солидно и соответствует образу издания, а два номера по 7680 страниц будут выглядеть провалом. Также на данном графике присутствует рост показателей в промежутках весна (апрель-май) и осень (сентябрь-ноябрь), что было отображено в теории на рис. 1.

Таблица 1

Table 1

Изменения общего объема и рекламного объема изданий «NetWorker», «Status» и «LEADERSTODAY» за 2018 год

Changes in the total volume and advertising volume of «NetWorker», «Status» and «LEADERSTODAY» publications for 2018

\begin{tabular}{|c|c|c|c|c|c|c|c|c|c|c|c|c|}
\hline & & \multicolumn{11}{|c|}{ Номер } \\
\hline Издание & Параметры & 1 & 2 & 3 & 4 & 5 & 6 & 7 & 8 & 9 & 10 & 11 \\
\hline \multirow[t]{2}{*}{$\begin{array}{l}\text { LEADERSTO } \\
\text { DAY (ранее } \\
\text { СТИЛЬ) }\end{array}$} & $\begin{array}{l}\text { общий } \\
\text { объем } \\
\text { (страниц) }\end{array}$ & 124 & 118 & 108 & 116 & 116 & 124 & 156 & 132 & 124 & 148 & 124 \\
\hline & $\begin{array}{l}\text { рекламный } \\
\text { объем } \\
\text { (страниц) }\end{array}$ & 65 & 51 & 57 & 56 & 57 & 66 & 85 & 67 & 79 & 81 & 69 \\
\hline \multirow[t]{2}{*}{ Status } & $\begin{array}{l}\text { общий } \\
\text { объем } \\
\text { (страниц) }\end{array}$ & 92 & 102 & 100 & 100 & 100 & 100 & 100 & & & & \\
\hline & $\begin{array}{l}\text { рекламный } \\
\text { объем } \\
\text { (страниц) }\end{array}$ & 42 & 45 & 40 & 30 & 55 & 42 & 34 & & & & \\
\hline \multirow[t]{2}{*}{ NetWorker } & $\begin{array}{l}\text { общий } \\
\text { объем } \\
\text { (страниц) }\end{array}$ & 86 & 70 & 88 & 94 & 70 & 74 & 62 & 72 & 62 & 64 & 82 \\
\hline & $\begin{array}{l}\text { рекламный } \\
\text { объем } \\
\text { (страниц) }\end{array}$ & 54 & 41 & 42 & 52 & 45 & 56 & 29 & 38 & 45 & 43 & 55 \\
\hline
\end{tabular}

Источник: составлено авторами по материалам [сайт журнала NetWorker; сайт журнала Status; сайт журнала LEADERSTODAY].

Что касается журнала Status, также есть ряд точек совпадений. Во-первых, начало года отличается низкими показателями. Во-вторых, летний промежуток также совпадает в плане снижения рекламного наполнения. Пять из семи выпусков сдвоенные - то есть над ними работали два месяца, что позволяет стабилизировать общий объем в течение года.

Если же говорить о NetWorker, также есть спад общего объема и рекламного объема (более ощутим спад рекламного материала) летом, также есть наращивание показателя с сентября по ноябрь. Есть расхождения с выдвинутой теорией на стадии начала года, но это объясняется тем, что издание выпускает один номер декабрь-январь.

В целом можно сказать, что большая часть теории колебания в тематическом направлении экономики подтверждаются. Для преодоления летнего и январского спада издания используют метод сдвоенного номера, а также стабилизируют объем за счет редакционных материалов, а если взять во внимание активное использование электронных ресурсов и прирост денежных средств от них, можно сказать, что электронная реклама покрывает расходы на увеличение качественного редакционного контента [Российская периодическая печать, 2019; Зверева, 2019]. 


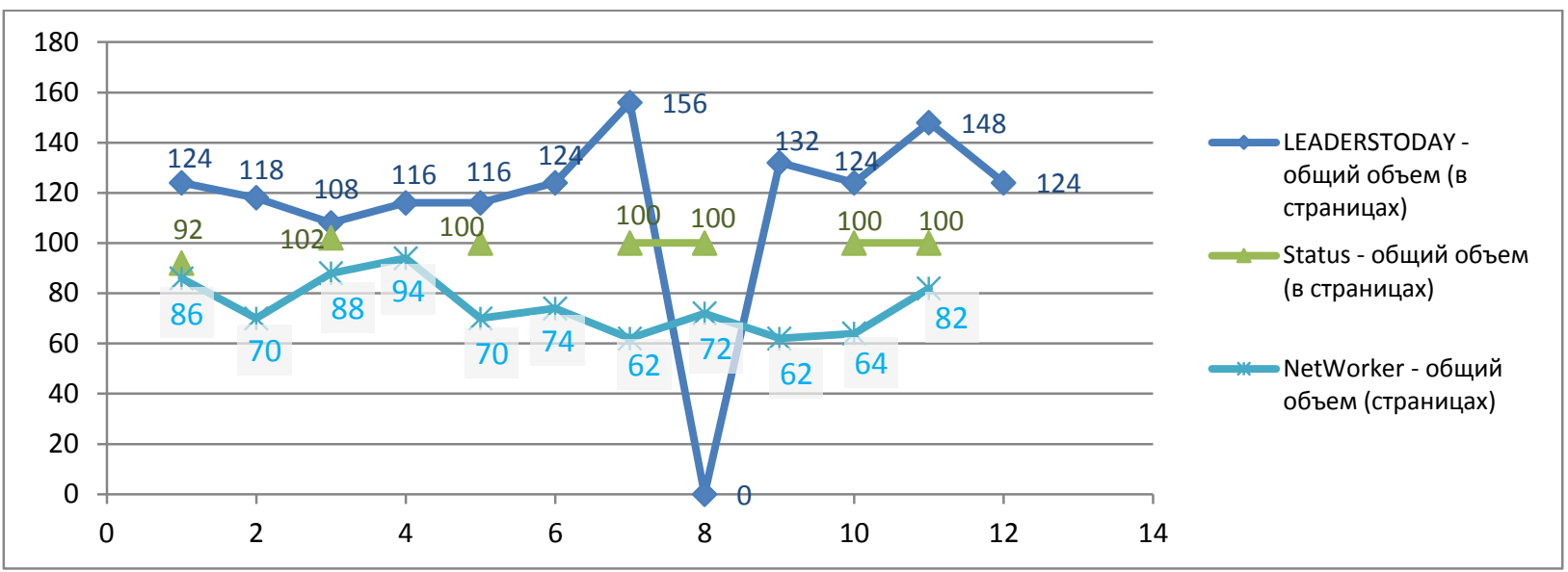

Рис. 2. Изменения общего объема наполнения в журналах «LEADERSTODAY», «Status» и «NetWorker» в течение 2018 года, согласно данным таблицы 1

Fig. 2. Changes in the total volume of filling in the magazines "LEADERSTODAY», «Status» and «NetWorker» during 2018, according to the data in Table 1

Источник: составлено автором на основе табл. 1.

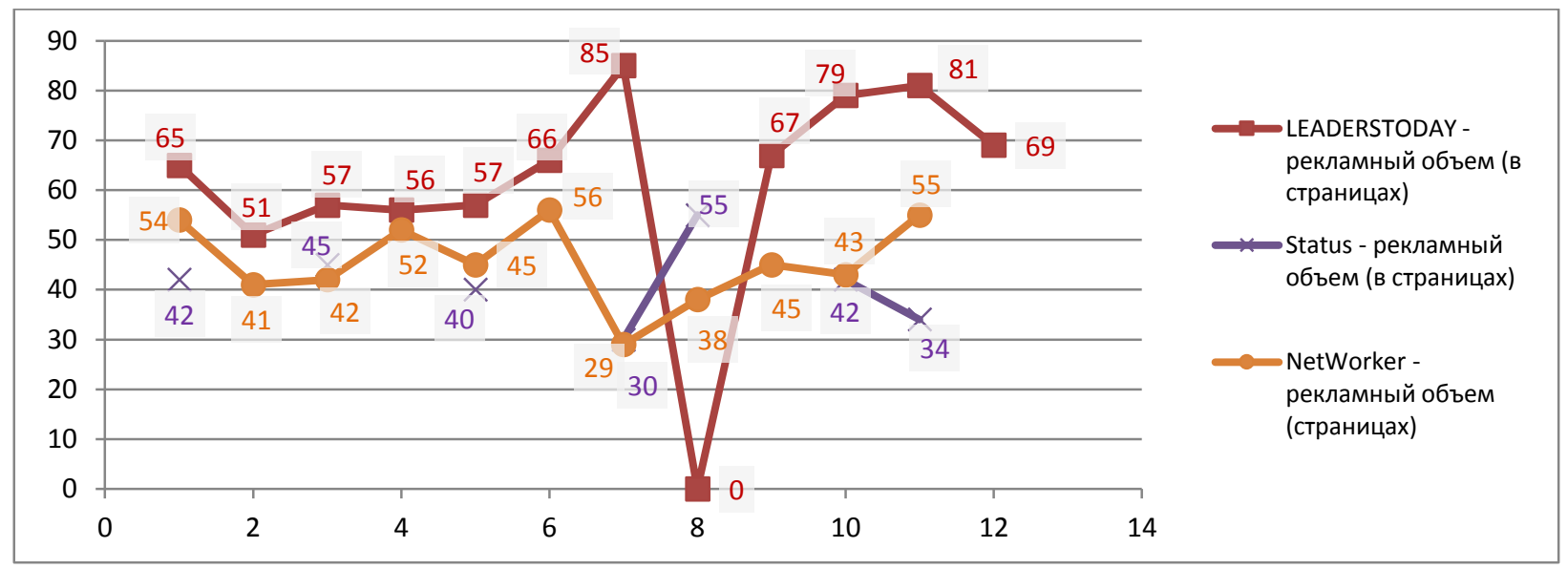

Рис. 3. Изменения рекламного объема наполнения в журналах «LEADERSTODAY», «Status» и «NetWorker» в течение 2018 года, согласно данным таблицы 1

Fig. 3.Changes in the advertising volume of content in the magazines «LEADERSTODAY», «Status» and «NetWorker» during 2018, according to the data in Table 1

Источник: составлено автором на основе табл. 1.

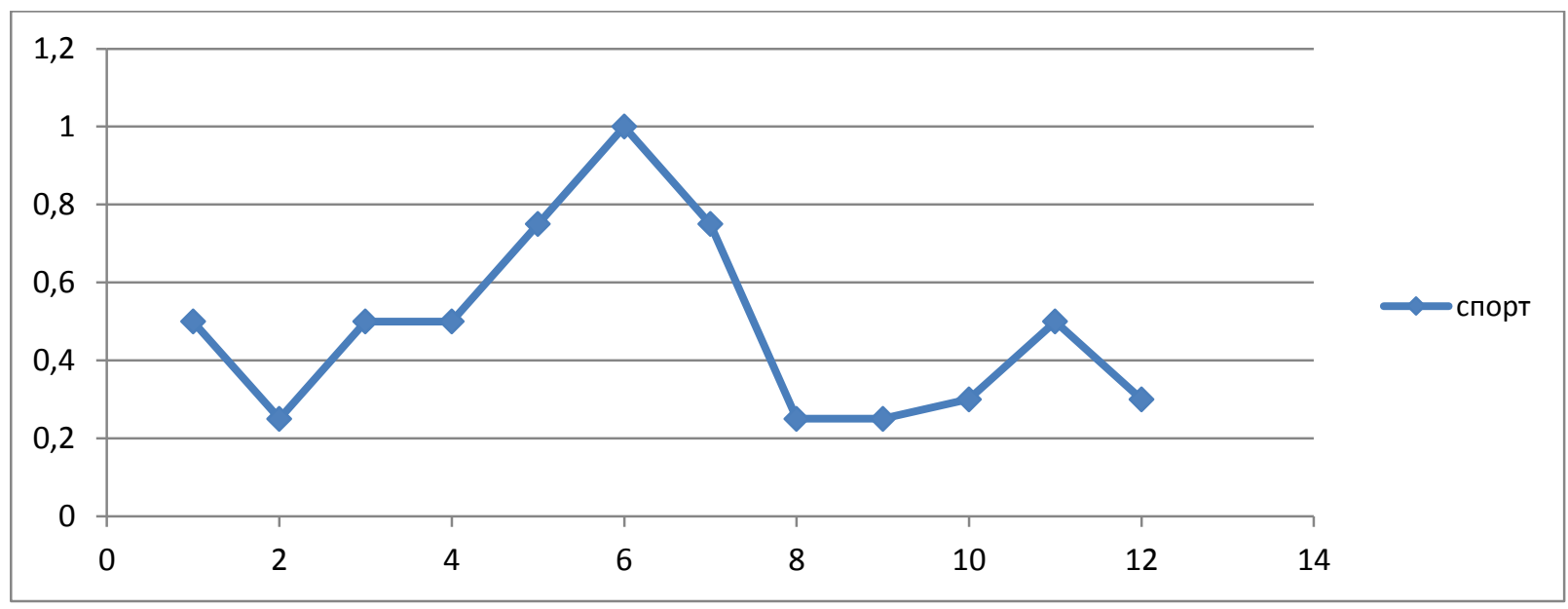

Рис. 4. Активность компаний, относящихся к разделу о спорте, в течение года

Fig. 4. Activity of companies related to the sports section during the year

Источник: составлено автором на основе теории. 
На данном рисунке пик максимальной активности выпадает на промежуток с марта по июнь (причина - большинство спортивных мероприятий и соревнований заканчиваются к началу лета), здесь можно привести много примеров: это и биатлон, футбольные, баскетбольные чемпионаты, зимние олимпийские игры и т. д. Также видны спады в промежутке с июля по август, в это время очень мало мероприятий и информационных новостей.

Для подтверждения вышепредставленного графика проведем анализ наполнения журналов, относящихся к спорту. На текущий момент изданий, занимающихся только спортивной тематикой, практически нет (или же издания есть, но отсутствует архив в свободном доступе), поэтому в качестве объекта изучения был взят сайт basketball.ru.com и его новостное наполнение за 2019 год. Результаты анализа представлены ниже на рисунке 5.

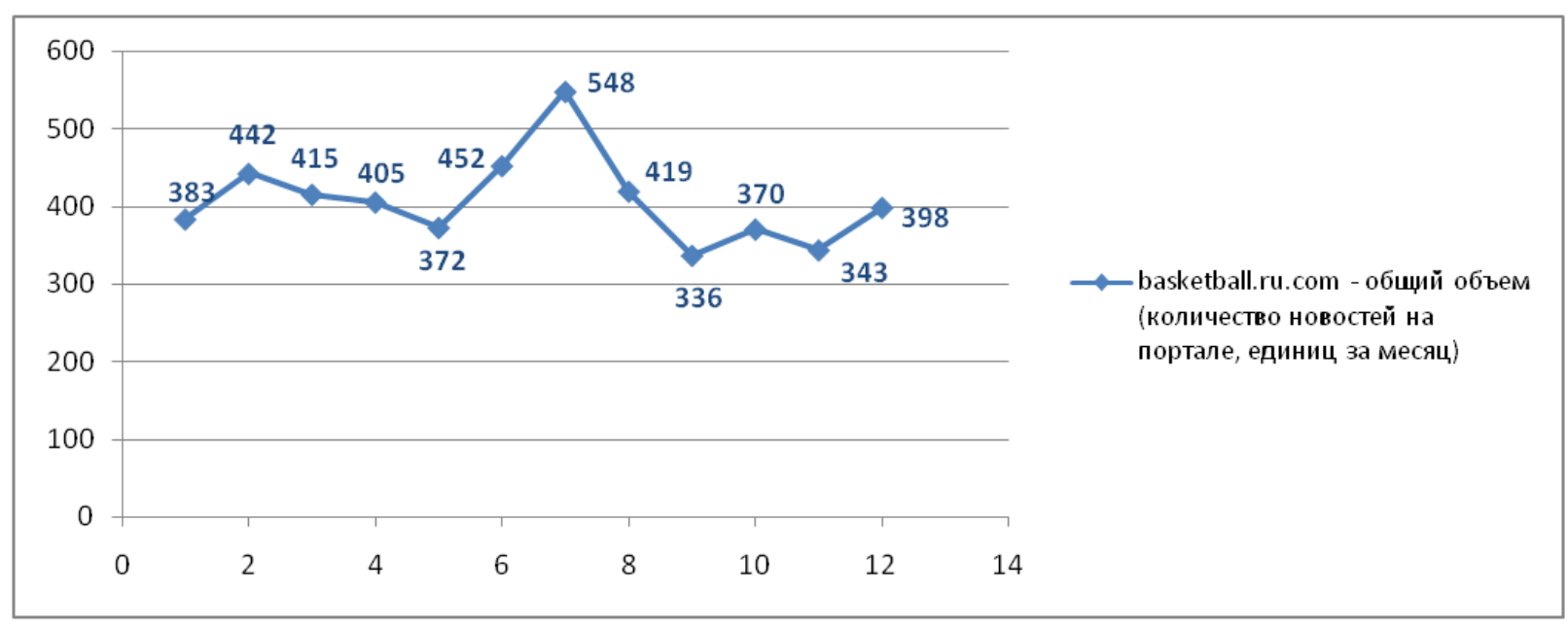

Рис. 5. Изменения информационного объема информационного ресурса в течение 2019 года

Fig. 5. Changes in the information volume of the information resource during 2019 Источник: составлено автором по материалам [сайт Basketball.ru.com].

Если объективно оценивать полученный результат анализа сайта, можно сказать, что также есть ряд точек, по которым выдвинутая теория колебания данной сферы подтверждается. Так, например, есть рост в весенней части, есть спад в осеннем промежутке. Есть небольшие расхождения: так, точка максимальной активности для данного спортивного ресурса находится не в июне, а в июле, но в обозначенной теории промежуток май-июль обозначен как высокоактивный в целом для всего спорта, так как хоккейный сезон заканчивается в начале мае, а футбольный - в середине.

Теперь, синхронизируя схемы двух разделов, получаем следующий результат, продемонстрированный на рисунке 6.

Как видно, при синхронизации двух разделов (относящихся к вышеизученным сферам) в рамках одного издания в теории можно стабилизировать объем в первую очередь общий, при оптимальном подходе также рекламный. Отчетливо видно следующее: где у одного раздела (сферы) наступает спад, там наступает высокая активность у другого раздела (сферы).

Если же говорить о расширении читательской аудитории и об интересе к такого рода проекту, стоит отметить следующее - в этом направлении очень важную роль будет играть тематический переход и сам контент (наполнение). Если разбирать данные нюансы на ранее начатом примере, а именно синхронизации экономики и спорта, здесь переход может иметь такие формы - например, экономика заканчивается материалом об анализе рынка недвижимости, а спорт начинается с материала о строительстве крупного спортивного объекта. Также у данных сфер есть ряд других точек соприкосновения: часть спортивных 
соревнований имеют призовой фонд от спонсоров (коммерческих компании), поэтому мероприятия имеют и спортивную, и экономическую составляющую. Что касается контента, его нужно детально прорабатывать, именно в плане уникальности (форма подачи, выработка фирменного стиля подачи материала) и проработанности (факты, цифры и комментарии экспертов) [Огилви, 2005; Доктор, 2013].

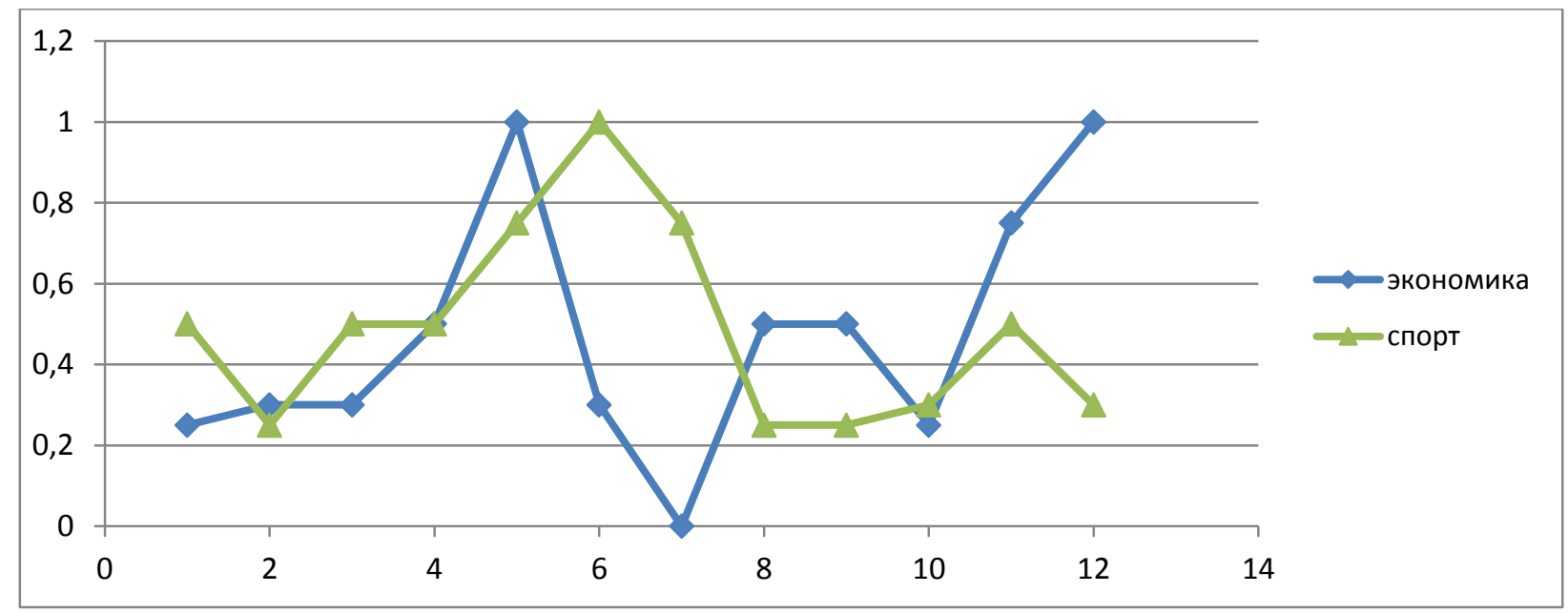

Рис. 6. Синхронизация активности двух разделов в рамках одного издания в течение года Fig. 6. Synchronization of the activity of two sections within one publication throughout the year

Источник: составлено автором на основе теории.

\section{Потенциальные экономические перспективы и сложности их достижения}

Во-первых, стабилизация и укрепление позиции на информационном рынке и расширение возможностей. Про стабилизацию внутреннего наполнения было уже сказано, но как это связанно с укреплением позиции на рынке? Стабилизация позволяет стабилизировать показатели - объема номера и среднегодовой объем выпуска, а также удерживать колебания наполнения на уровне 10-12\%. Данные показатели напрямую привязаны к статусу издания и к его позиции на рынке. Если крупное издание теряет стабильность в объеме и номера могут выходить то 80, то 100, то 60 страниц, то такое издание частично утрачивает позицию «сильного участника», и его могут начать расценивать как объект для поглощения другие участники информационного рынка. Еще Т. Амблер писал, что нужно ориентироваться на сильных игроков рынка, но изучать слабых для возможного поглощения [Амблер, 1999]. Казалось бы, такой подход устарел, но в 2017 году на открытой презентации компании «Реклама Онлайн» была озвучена следующая позиция: «Мы в кризис не уходим и не ослабляем свои позиции, мы поглощаем слабых». Поэтому стабильный объем - это своего рода показатель экономической стабильности и умелого управления. Что касается «расширения возможностей» - это спектр вариантов более продуктивного расширения возможностей на электронных платформах [Браславец, 2009]. Современные издания очень активно используют электронные платформы для получения дополнительных денежных ресурсов (digital доходы) [Российская периодическая печать, 2019]. Есть ряд примеров, когда издания кроме своего сайта также активно используют социальные сети и даже строят системы перехода с одного ресурса на другой. Так, например, журнал «Я Покупаю» кроме печатной версии продвигает фирменный сайт и активно использует площадки в социальных сетях (ВКонтакте и Instagram), или журнал Председатель, который кроме печатной рекламы также предлагает интернет-продвижение (официальный сайт), видео интервью (свой канал YouTube), а также рекламные кампании [Журнал «Я Покупаю»; Журнал Председатель]. При изучаемой системе издание может поделить сайт на две тематические части, и для каждой создать нужные платформы в социальных сетях. В потенциале это может привести к увеличению 
денежных поступлений за счет расширения диапазона охвата аудитории, а также посредством расширения вариативности услуг (отдельно печатная или электронная реклама, или совмещенный вариант). Для более точного понимания, если аудитория печатного ресурса это смежная аудитория (те, кому интересна и экономическая, и спортивная информация), то электронные площадки могут расширяться в своем тематическом пространстве и охватывать дополнительную (специальную) аудиторию.

Сложности данной перспективы: в материале отмечалось, что количество тематических разделов должно быть 2-3, данное ограничение связано с таким ключевым параметром, как контент. Если разделов очень много, и они относятся к разным отраслям, у руководства может возникнуть дефицит ресурсов (сотрудников) для создания действительно уникального, качественного и проработанного контента, вместо этого будет поверхностный и аналоговый контент. Так, Доктор К. отмечал, что трансформация в электронную форму массмедиа не произвела «революцию» в плане наполнения [Доктор, 2013]. В данном случае можно говорить, что ряд изданий при переходе в электронную форму утратил уникальность контента, многие стали однотипными, в таких параметрах как объем (короткие материалы), форма подачи (максимальная прагматичность), изученность (оперативно, но поверхностно). Возможно, именно уникальный (для каждого печатного издания) стиль подачи материала стал одним из ключевых параметров того, почему они остаются конкурентоспособны сегодня [Конев, 2018].

Во-вторых, поддержание конкурентоспособности бренда издания посредством создания условий для циклического обновления. В рамках межотраслевого существования формируется два крупных раздела, и у издания есть возможность проводить обновления и перезагрузку одного раздела, опираясь на стабильную экономическую работу второго [Хмелев, 2020]. Если говорить о смысле - это поддержание конкурентоспособности бренда, так как со временем может устаревать форма подачи материала, сам контент, и актуальность тем, а также есть вероятность, что часть рынка перестроится или исчезнет. Например, сейчас, после запуска всероссийской цифровизации телевидения, всё, что касается аналогового вещания, становится неактуальным и устаревшим, а компании, работавшие в этом сегменте, вынуждены перепрофилироваться под «цифру». Соответственно и издания должны следить за такими изменениями и поступательно обновляться, но если издание узкопрофильное, и тематика строго привязана к одной отрасли, то единственный путь - это полномасштабная перезагрузка бренда (ребрендинг), что может отрицательно восприняться действующими партнерами (рекламодателями), читательской аудиторией и соответственно привести к их сокращению. [Аакер, 2003]. Стоит также понимать, что процесс формирования новой базы (новых рекламодателей) -это процесс, который требует времени (от одного до трех месяцев), и может возникнуть ситуация, когда старые клиенты ушли, а новых еще нет [Портер, 2005; Мудров, 2008; Хмелев, 2020]. Данная модель дает условия для плавного обновления части актива в циклическом режиме.

Сложности данной перспективы: данная перспектива требует постоянного контроля и учёта статистических данных медиаресурса для того чтобы понимать, в какой стадии жизненного цикла находится каждый раздел, стоит отметить, что жизненный цикл средства массовой информации составляет 15 лет (пик возможностей 7,5-10 лет). Также нужен глубокий маркетинговый анализ рынка с целью изучения изменений - аудитории, стилистики, актуальности темы, трансформация сферы / отрасли и ключевые мероприятия, в целом все ключевые параметры [Котлер, 1991].

В-третьих, потенциальная перспектива укрупнения или расширения. Когда идет речь о укрупнении и расширении, обычно в сфере массмедиа имеются в виду два варианта: первый приобретения уже существующего издания и второй - создания нового издания [Хмелев, 2017]. Но данная система дает третий вариант - это укрупнение посредством деления межотраслевого издания на несколько узкопрофильных. Процесс, когда название издания сохраняется в качестве общего названия для целого ряда специализированных тематических журналов (каждый тематический раздел становится самостоятельным специализированным 
журналом), посредством этого происходит увеличение количества рекламодателей, увеличение охвата аудитории и количества сегментов рынка [Хмелев, Хмелева, 2017; Портер]. Но стоит отметить важное отличие данного процесса от метода создания нового издания - это минимальная вероятность наступления одного из сценариев теории каннибализма. Данная теория, согласно Ламбену, означала следующее: «компания, имеющая успешную товарную марку, при создании новой, сильно рискует, потому что новая марка может перетянуть как клиентов конкурентов, так и клиентов уже успешно существующей марки» [Ламбен, 1996, c. 442]. При создании нового издания есть высокая вероятность наступления одного из сценариев, в то время как при разделении журнала на тематические издания такая угроза сведена к минимуму. Так как, если внутри одного издания разделы не имели точек соприкосновений (общих рекламодателей), или их было крайне мало, то этот факт останется и при разделении журнала.

Для реализации этой перспективы требуются следующие условия:

- во-первых, изначально при создании издания было заложено два (от 2 до 3) тематических раздела. Например, разделы «Бизнес»и «Строительство» в рамках делового журнала или разделы про «Киберспорт» и «Инновационные технологии» в рамках технического журнала. В практике можно такое встретить, например, у издания «Коммерсант» - существует «Коммерсантъ Деньги» и «Коммерсанть Власть» [Коммерсантъ].

- во-вторых, издание стабилизировало объем (то есть количество полос) каждого раздела на определенной отметке, которая равна объему самостоятельного издания малого или среднего типа (примечание: объем малого издания равен 40-60 полос, объем среднего издания равен 60-80 полос). Так, например, чтобы считаться солидным или крупным изданием, журналу нужен средний объем в радиусе 120-180 страниц, таким образом, при двух разделах объем одного раздела в среднем будет равен 60-90, при трех - 40-60 страниц. Этот показатель определяет, что каждый раздел может существовать как отдельный тематический журнал (проект), и при такой форме существования увеличивать количество новых рекламодателей (которые ранее не привлекались, так как у них отсутствовал интерес из-за того, что журнал охватывал другие тематики и не был узкопрофильным). Таким образом, для укрупнения нужны статистические данные, которые позволяли бы понять динамику работы каждого раздела журнала, а именно:

- средний объем (всего / рекламы) раздела в течение года;

- радиус колебания объёма (общего / рекламного) каждого раздела в течение года;

- динамика изменения объема раздела периодом за последние год-два года.

Ниже на рисунке 7 схематически представлен пример данного процесса.

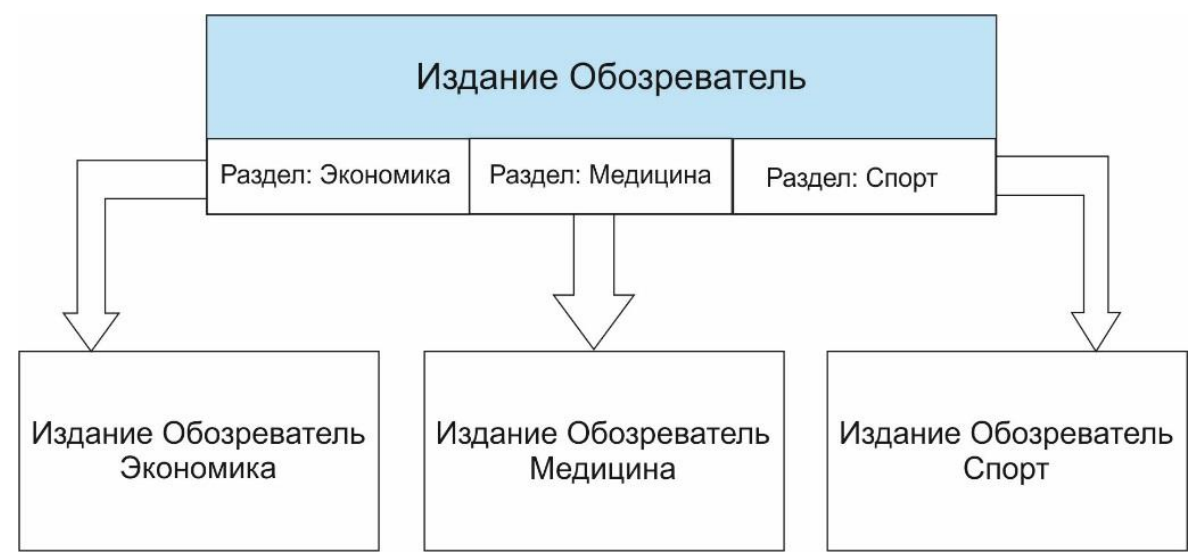

Рис. 7. Теоретический пример процесса по делению издания на несколько (обособленное существование каждого тематического раздела)

Fig. 7. A theoretical example of the process of dividing a publication into several (separate existence of each thematic section)

Источник: составлено автором на основе теории. 
Пример, продемонстрированный на рисунке 7, показывает, что издание может развиваться, сохраняя свое имя, добавив к нему тематическое примечание. Например, журнал «Обозреватель» преобразуется в издания: «Обозреватель: экономика», и «Обозреватель: спорт» [Хмелев, Хмелева, 2017]. С экономической точки зрения происходит следующее: издание использует межотраслевую форму для снижения прямой конкуренции и закрепления на рынке, затем происходит деление с дальнейшими тематическими расширениями в области целевой аудитории и рекламодателей.

Данный процесс может протекать как в вышеописанной форме, так и несколько иначе, если быть точным, то внутри каждого тематического раздела могут сформироваться подразделы так, например, в разделе о медицине может быть два подраздела «Здоровье» и «Красота». И тогда схема деления может происходить согласно рисунку 8.

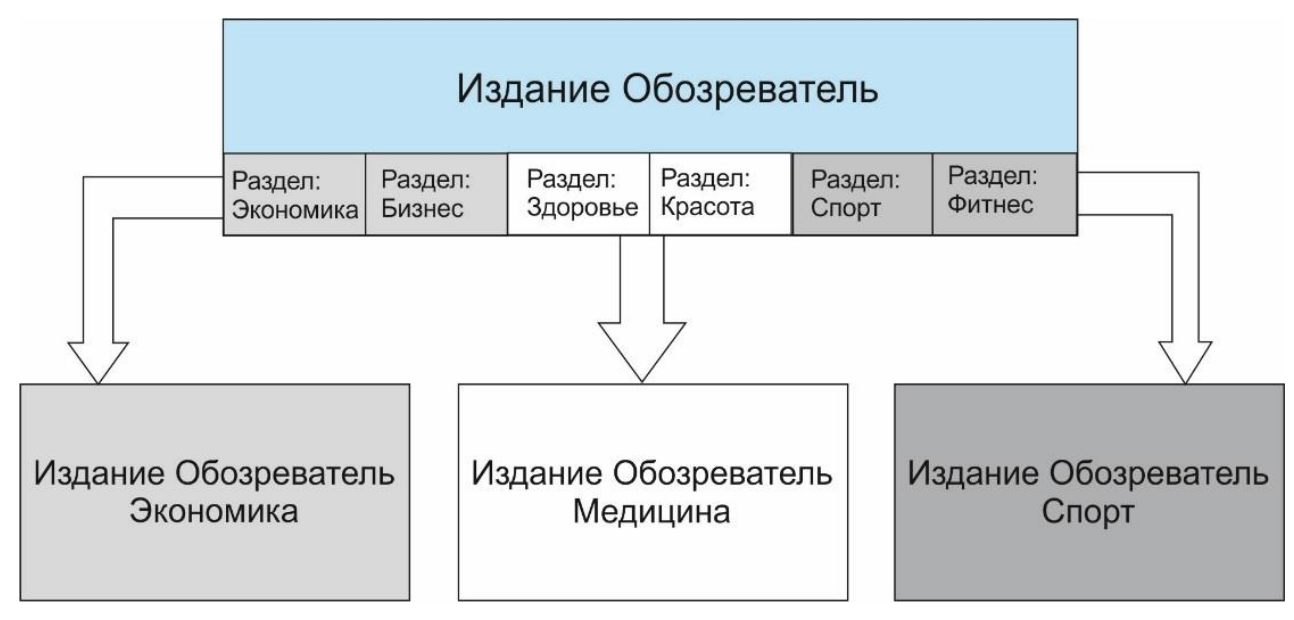

Рис. 8. Укрупнение до обособленного существования разделов, внутри которых группы подразделов

Fig. 8. Consolidation to the isolated existence of sections, within which there are groups of subsections

Источник: составлено автором на основе теории.

Сложности данной перспективы: для реализации данной перспективы нужен сбор и анализ статистических данных о состоянии каждого раздела, а также понимание того, соединение каких разделов (подразделов) будет гармонично. Так как в данном конкретном случае есть вероятность наступления одного из сценариев теории каннибализма, при большом количестве подразделов может формироваться плотная взаимосвязь и есть вероятность наличия множества малых точек соприкосновения, и все будет зависеть от количества этих точек и их материального значения в экономическом плане [Ламбен, 1996]. Так, например, если разбирать рисунок 8, может образоваться вопрос «инновации в медицине» - это одновременно и вопрос медицины, но также и экономики (так как это одно из направлений инвестиций). Именно диагностика таких точек важна, потому как при большом их количестве в них может происходить деление до 40 \% рекламы от объема каждого из разделов.

\section{Заключение}

Минимальная прямая конкуренция с крупными изданиями, стабилизация объемов (общих и рекламных), широкий охват аудитории - данные положительные моменты говорят о том, что рассматриваемая модель существования имеет положительный потенциал. Если оценивать перспективы - модель дает несколько вариантов для дальнейшей работы, а именно «циклическое обновление» или «деление на несколько СМИ». Уверенные руководители могут выбрать путь приумножения актива, в то время как осторожные могут выбрать стратегию обновления и ожидания подходящего времени. Получается, что изучаемая модель подходит для разных типов руководителей и разных стратегий развития. Из отрицательных моментов 
можно выделить три сложности - маркетинговый анализ рынка, статистический анализ актива и проработку наполнения, но при этом все эти сложности возможно решить грамотным подбором кадров.

\section{Список источников}

1. BASKETBALL.RU. URL: http://basketball.ru.com/ (дата обращения: 10.11.2020).

2. Журнал «Leaderstoday» URL: https://leaderstoday.ru/. (7.11.2020).

3. Журнал NetWorker URL: https://leaderstoday.ru/. (10.02.2021).

4. Журнал Shopping Guide «Я Покупаю» URL: http://nsk.yapokupayu.ru/. (9.08.2020).

5. Журнал Status URL: http://status-media.com/o-zhurnale/. (7.11.2020).

6. Журнал Инфосфера URL: http://infosfera.sfo.ru/. (9.10.2016).

7. Журнал «Председатель» URL: https://predsedatel-apk.ru/. (12.08.2020).

8. Коммерсантъ. URL: https://www.kommersant.ru/archive (15.11.2020). 22.01.2021).

9. Прайс-лист «АиФ на Оби» URL: https://nsk.aif.ru/static/2965172 (дата обращения:

10. Федеральный закон от 13.03.2006 N 38-Ф3 (ред. от 31.07.2020) «О рекламе». URL: http://www.consultant.ru/document/cons_doc_LAW_58968/f68afc90fd06f2e62b3e3cb45714c287c5e44086/ (28.09.2020).

\section{Список литературы}

1. Амблер Т. 1999. Практический маркетинг. СПб.: Издательство «Питер», 400. (Ambler T. 1996. The Financial Times Guide to Marketing: from advertising to zen. London, Pitman publishing, 400).

2. Аакер Д.А. 2003.Создание сильных брендов. М.: Издательский Дом Гребенникова, 340.

3. Браславец Л.А. 2009. Социальные сети как средства массовой информации: к постановке проблемы. Вестник ВГУ. Серия: Филология. Журналистика. 1: 125-132.

4. Доктор К. 2013. Ньюсономика. Двенадцать трендов, которые изменят новости. М.: РИА «Новости», 352.

5. Зверева Е.А. 2019. Бумажная пресса в условиях цифровизации медиасистемы. В кн.: «Журналистика - 2019: состояние, проблемы, перспективы». Материалы 21-й международной научнопрактической конференции. Минск, Изд-во БГУ: 137-141.

6. Конев Е. 2018. Прогнозируемые векторы развития зарубежных медиа. В кн.: «Журналистика 2018: состояние, проблемы, перспективы». Материалы 20-й международной научно-практической конференции. Минск, Изд-во БГУ: 294-297.

7. Котлер Ф. 1991. Основы маркетинга. М.: Издательство «Прогресс».

8. Ламбен Жан-Жак. 1996. Стратегический маркетинг. Европейская перспектива. СПб.: Наука, 589. (Lambin Jean-Jacques. 1994. Le marketing strategique. Une perspective europeenee. Ediscience international, 589.).

9. Мудров А.Н. 2008. Основы рекламы: учебник. 2-е изд. М.: Магистр.

10.Огилви Д. 2005. Тайны рекламного двора - советы старого рекламиста. М.: Ассоциация работников рекламы, 61.

11.Портер Майкл Е. 2005. Конкурентная стратегия: Методика анализа отраслей и конкурентов. М.: Альпина Бизнес Букс, 454. (Michael E. Porter. 1998. Competitive strategy: Techniques for Analyzing Industries and Competitors. The Free Press, 454.).

12.Российская периодическая печать. 2020. Состояние, тенденции и перспективы развития в 2019 году. Отраслевой доклад, под общ. ред. В.В. Григорьева. М.: Федеральное агентство по печати и массовым коммуникациям, 123.

13.Тамберг В., Бадьин А. 2005. Бренд. Боевая машина бизнеса. М.: «Олимп-Бизнес», 240.

14.Хмелев А.В. 2017. Анализ проблем и рисков процесса укрупнения и усиления современных печатных СМИ. Вестник НГУЭУ, 3: 299-310.

15. Хмелев А.В. 2020. Развитие брендов печатных средств массовой информации. e-FORUM, 4 (13).

16. Хмелев А.В., Хмелева И.В. 2017. Исследования инструментов воздействия и способов ведения конкурентной борьбы изданий. В кн.: Современное коммуникационное пространство: анализ состояния и тенденции развития - 2017. Материалы Международной научно-практической конференции. В 2-х частях. Новосибирск, Изд-во НГПУ: 271-274. 


\section{References}

1. Ambler T. 1999. Prakticheskiy marketing. SPb.: Izdatel'stvo «Piter», 400. (Ambler T. 1996 The Financial Times Guide to Marketing: from advertising to zen. London, PITMAN PUBLISHING, 1996. 400).

2. Aaker D.A. 2003.Sozdanie sil'nykh brendov [Creating strong brands]. M.: Izdatel'skiy Dom Grebennikova, 340.

3. Braslavets L.A. 2009. Sotsial'nye seti kak sredstva massovoy informatsii: k postanovke problemy. Vestnik VGU. Seriya: Filologiya. Zhurnalistika [Social networks as mass media: to the problem statement. Vestnik VSU. Series: Philology. Journalism], 1: 125-132.

4. Doktor K. 2013. N'yusonomika. Dvenadtsat' trendov, kotorye izmenyat novosti [Newsonomics. Twelve trends that will change the news]. M.: RIA «Novosti», 352.

5. Zvereva E.A. 2019. Bumazhnaya pressa $\mathrm{v}$ usloviyakh tsifrovizatsii mediasistemy. $\mathrm{V} \mathrm{kn}$.: «Zhurnalistika-2019: sostoyanie, problemy, perspektivy» - 2019. Materialy 21-y mezhdunarodnoy nauchnoprakticheskoy konferentsii [Paper press in the context of digitalization of the media system. Proceedings of the 21st international scientific and practical conference «Journalism - 2019: state, problems, prospects»]. Minsk, Izd-vo BGU: 137-141.

6. Konev E. 2018. Prognoziruemye vektory razvitiya zarubezhnykh media. V kn.: «Zhurnalistika-2018: sostoyanie, problemy, perspektivy» - 2018. Materialy 20-y mezhdunarodnoy nauchno-prakticheskoy konferentsii [Forecasted vectors of development of foreign media. Materials of the 20th international scientific-practical conference «Journalism - 2018: state, problems, prospects»]. Minsk, Izd-vo BGU: 294-297.

7. Kotler F. 1991. Osnovy marketinga. M.: Izdatel'stvo «Progress».

8. Lamben Zhan-Zhak. 1996. Strategicheskiy marketing. Evropeyskaya perspektiva. SPb.: Nauka, 589. (Lambin Jean-Jacques. 1994. Le marketing strategique. Une perspective europeenee. Ediscience international, 589.).

9. Mudrov A.N. 2008. Osnovy reklamy: uchebnik [Basics of advertising: a textbook]. 2-e izd. M.: Magistr.

10.Ogilvi D. 2005. Tayny reklamnogo dvora - sovety starogo reklamista [Secrets of the advertising yard-tips of the old advertiser]. M.: Assotsiatsiya rabotnikov reklamy, 61.

11.Porter Maykl E. 2005. Konkurentnaya strategiya: Metodika analiza otrasley i konkurentov. M.: Al'pina Biznes Buks, 454. (Michael E. Porter. 1998. COMPETITIVE STRATEGY: Techniques for Analyzing Industries and Competitors. The Free Press, 454.).

12. Rossiyskaya periodicheskaya pechat'. 2020. Sostoyanie, tendentsii i perspektivy razvitiya v 2019 godu. Otraslevoy doklad, pod obshch. red. V. V. Grigor'eva. M.: Federal'noe agentstvo po pechati i massovym kommunikatsiyam [Russian periodicals. Status, trends and development prospects in 2019. Industry report], 123.

13. Tamberg V., Bad'in A. 2005. Brend. Boevaya mashina biznesa [Brand. Combat machine of business]. M.: «Olimp-Biznes», 240.

14. Khmelev A.V. 2017. Analiz problem i riskov protsessa ukrupneniya i usileniya sovremennykh pechatnykh SMI. Vestnik NGUEU [Analysis of problems and risks of the process of consolidation and strenthening of modern print media. Vestnik NSUEM], 3: 299-310.

15. Khmelev A.V. 2020. Razvitie brendov pechatnykh sredstv massovoy informatsii. e-FORUM [Print media brand development. e-forum], 4 (13).

16. Khmelev A.V., Khmeleva I.V. 2017. Issledovaniya instrumentov vozdeystviya i sposobov vedeniya konkurentnoy bor'by izdaniy. V kn.: Sovremennoe kommunikatsionnoe prostranstvo: analiz sostoyaniya i tendentsii razvitiya - 2017. Materialy Mezhdunarodnoy nauchno-prakticheskoy konferentsii. V 2kh chastyakh [Research of tools of influence and methods of conducting competitive struggle between publications. Modern communication space: analysis of the state and development trends], Novosibirsk: Izdvo NGPU: 271-274.

\section{ИНФОРМАЦИЯ ОБ АВТОРЕ}

Хмелев Алексей Вячеславович, старший преподаватель кафедры систем автоматизированного проектирования Сибирского государственного университета телекоммуникации и информатики (ФГБОУ ВО СибГУТИ), г. Новосибирск, Россия

\section{INFORMATION ABOUT THE AUTHOR}

Alexey V. Khmelev, Senior Lecturer of the Department of computer aided design systems Siberian State University of Telecommunications and Information Sciences, Novosibirsk, Russia 